\title{
Circadian rhythm of the signal averaged electrocardiogram and its relation to heart rate variability in healthy subjects
}

\author{
M Nakagawa, T Iwao, S Ishida, H Yonemochi, T Fujino, T Saikawa, M Ito
}

\begin{abstract}
Objective-To examine the circadian variation in the signal averaged electrocardiogram (saECG) and heart rate variability and investigate their relations in healthy subjects.

Methods-24 hour ECGs were obtained with a three channel recorder using bipolar $\mathrm{X}, \mathrm{Y}$, and $\mathrm{Z}$ leads in 20 healthy subjects. The following variables were determined hourly: heart rate, filtered QRS (f-QRS) duration, low and high frequency components of heart rate variability (LF and $H F$ ), and the LF/HF ratio.

Results-Heart rate, $\mathrm{f}-\mathrm{QRS}$ duration, $\mathrm{HF}$, and the LF/HF ratio showed significant circadian rhythms, as determined by the single cosinor method. Heart rate and the LF/HF ratio increased during daytime, and $f-Q R S$ duration and $H F$ increased at night. f-QRS duration was negatively correlated with heart rate $(r=0.95$, $\mathrm{p}<0.001)$ and the LF/HF ratio $(r=0.94$, p $<0.001)$ and positively with HF $(r=0.93, \mathrm{p}<0.001)$.

Conclusions-f-QRS duration has a significant circadian rhythm in healthy subjects and is closely related to the circadian rhythm of autonomic tone.

(Heart 1998;79:493-496)
\end{abstract}

Keywords: signal averaged ECG; f-QRS duration; circadian rhythm; heart rate variability

Signal averaged electrocardiography (saECG) is a non-invasive method of detecting the substrate for malignant ventricular arrhythmias and is widely used to identify individuals at high risk for such arrhythmias and for sudden cardiac death. ${ }^{1-5}$ Although the saECG has been assumed to measure fixed parameters, several studies have shown that these are altered by changes in factors such as heart rate and autonomic tone..$^{6-8}$ Analysis of heart rate variability has been used to evaluate cardiac autonomic tone..$^{9-11}$ Heart rate, heart rate variability, cardiac autonomic tone, and ventricular arrhythmias are known to have a circadian rhythm, ${ }^{12-16}$ but information on the possibility of a circadian rhythm of the saECG and on the contribution of circadian fluctuations in autonomic function to the saECG is limited. We investigated whether the saECG has a circadian rhythm in healthy subjects and examined the relation between circadian fluctuations of the saECG and heart rate variability.

\section{Methods}

STUDY POPULATION

We analysed 24 hour ECG recordings obtained in 44 healthy volunteers (28 men and 16 women, mean age (SD): 28.2 (3.3) years) in whom no abnormalities were detected by the medical history, physical examination, biochemical profile, 12 lead ECG, echocardiogram, or chest $x$ ray. No subjects were on drug treatment.

\section{ANALYSIS OF 24 HOUR ECG RECORDINGS}

The 24 hour ECG recordings were made with a three channel recorder (model 459, Del Mar Avionics, Irvine, California, USA) using bipolar leads X, Y, and Z.

\section{saECG analysis}

Signal averaging was performed on the data obtained from the first 500 seconds of every hour over the 24 hour period and filtered with a bidirectional filter at 40 to $250 \mathrm{~Hz}$. The filtered leads were combined to form a vector as: $\sqrt{\mathrm{X}^{2}+\mathrm{Y}^{2}+\mathrm{Z}^{2}}$. The QRS onset and offset were determined by a computer algorithm. The computer determined QRS offset point was checked visually and if incorrect, the actual QRS offset point was determined manually. If the terminal portion of the QRS - which can be affected by the noise level - was too small to permit accurate determination, the data were excluded from analysis. Data with a noise level greater than $1 \mu \mathrm{V}$ were also excluded from analysis.

\section{Heart rate variability analysis}

The power spectrum of the RR intervals was computed by a fast Fourier transformation and expressed as the square root of the areas under the power spectrum. We calculated the power of the low frequency component (LF, 0.04 to $0.15 \mathrm{~Hz}$ ) and the high frequency component (HF, 0.15 to $0.40 \mathrm{~Hz}$ ) for the first 300 seconds of every hour over the 24 hour period and analysed the mean hourly values. The ratio of the $\mathrm{LF}$ to $\mathrm{HF}$ components $(\mathrm{LF} / \mathrm{HF})$ was also determined for the first 300 seconds of each hour. Measures of heart rate variability were transformed by a natural logarithm because their distributions were skewed. We selected only data in which the heart rate, the baseline of ECGs, and the configuration of QRS-T waves were stable for at least 10 minutes, which suggests the absence of any abrupt change in posture or autonomic activity. We excluded data from 24 subjects because the saECG and heart rate variability data were available for less 

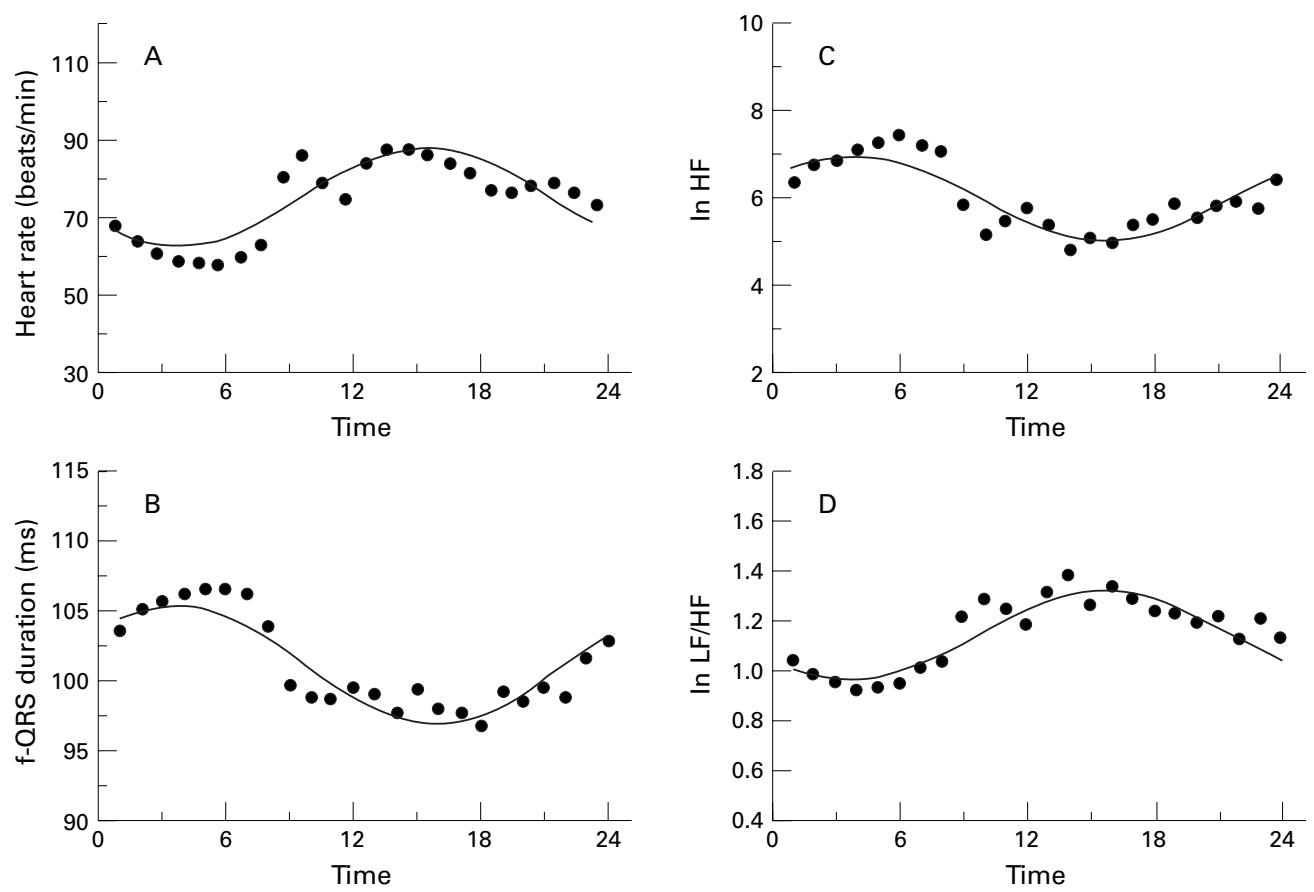

Figure 1 Circadian rhythm of the hourly means of heart rate $(A), f-Q R S$ duration $(B), \ln H F(C)$, and $\ln L F / H F(D)$ in 20 subjects. Solid lines represent curves fitted to the data by the single cosinor method. LF and HF, low and high frequency components, respectively, of heart rate variability; LF/HF, LF to $H F$ ratio.

than 21 of 24 hours. Thus we analysed data obtained in the remaining 20 subjects.

\section{STATISTICAL ANALYSIS}

The results are means (SD) unless otherwise specified. Heart rate, heart rate variability indices, and the filtered QRS (f-QRS) duration from the saECG were averaged on an hourly basis. The hourly mean data were analysed by the single cosinor method, ${ }^{17}$ in which a least squares procedure is used and a cosine function is fitted to the data. This model is characterised by three parameters: (1) the mesor, the rhythm determined average; (2) the amplitude, one half of the difference between the highest and the lowest values in a rhythm defined by the cosine function; and (3) the acrophase, the lag from the reference time point (midnight) to the time of the highest value in the cosine model fitted to the data. The significance of the circadian rhythms was evaluated by the zero amplitude test.

The relation between $f-Q R S$ duration and heart rate and heart rate variability was evaluated by linear regression analysis using hourly mean group data and hourly data obtained in individual subjects. Data were analysed by the Student's $t$ test. A p value $<0.05$ was considered statistically significant.

Table 1 Chronobiological parameters of circadian rhythm

\begin{tabular}{lccll}
\hline & Mesor & Amplitude & Acrophase & p value \\
\hline Heart rate (beats/min) & 73.7 & 12.5 & $14: 58$ & $<0.0001$ \\
1n LF & 6.65 & 0.14 & $06: 29$ & 0.18 \\
1n HF & 6.01 & 0.99 & $02: 59$ & $<0.0001$ \\
1n LF/HF & 1.15 & 0.18 & $14: 38$ & $<0.0001$ \\
f-QRS duration (ms) & 101.1 & 4.3 & $03: 12$ & $<0.0001$ \\
\hline
\end{tabular}

The $\mathrm{p}$ values indicate the significance of circadian rhythm of the parameter.

$\mathrm{LF}$, low frequency component; HF, high frequency component; LF/HF, LF to HF ratio.

\section{Results}

CIRCADIAN RHYTHM OF HEART RATE, HEART RATE VARIABILITY, AND $f-Q R S$ DURATION Heart rate, $\mathrm{HF}$, the $\mathrm{LF} / \mathrm{HF}$ ratio, and $\mathrm{f}-\mathrm{QRS}$, but not LF, showed significant circadian rhythms (fig 1). HF and $\mathrm{f}-\mathrm{QRS}$ duration increased at night and decreased during the day, whereas heart rate and the $\mathrm{LF} / \mathrm{HF}$ ratio were greater during the day than at night. The chronobiological parameters characterising the circadian rhythms of the variables studied are summarised in table 1. The acrophases of HF and $f-Q R S$ duration were similar, as were those of heart rate and the $\mathrm{LF} / \mathrm{HF}$ ratio.

Figure 2 shows the saECG recordings obtained in a 24 year old healthy woman at 05:00 and 11:00.

CORRELATION BETWEEN $\mathrm{A}$-QRS DURATION AND HEART RATE VARIABILITY

f-QRS duration was negatively correlated with heart rate $(r=0.95, \mathrm{p}<0.001)$ and the $\mathrm{LF} / \mathrm{HF}$ ratio $(r=0.94, \mathrm{p}<0.001)$, and positively with $\mathrm{HF} \quad(r=0.93, \mathrm{p}<0.001)$ (fig 3). $\mathrm{f}-\mathrm{QRS}$ duration was not correlated with LF. When the hourly data in individual subjects were analysed, $\mathrm{f}-\mathrm{QRS}$ duration was positively correlated with LF in eight of 20 subjects (40\%) and with $\mathrm{HF}$ in $17(85 \%)$, and negatively correlated with heart rate in all subjects and with the LF/HF ratio in $18(90 \%)$. In none of the subjects was f-QRS duration negatively correlated with LF or $\mathrm{HF}$, or positively correlated with heart rate or the $\mathrm{LF} / \mathrm{HF}$ ratio.

\section{Discussion}

Healthy subjects showed a significant circadian rhythm in the f-QRS duration of the saECG that was closely related to the circadian rhythm 

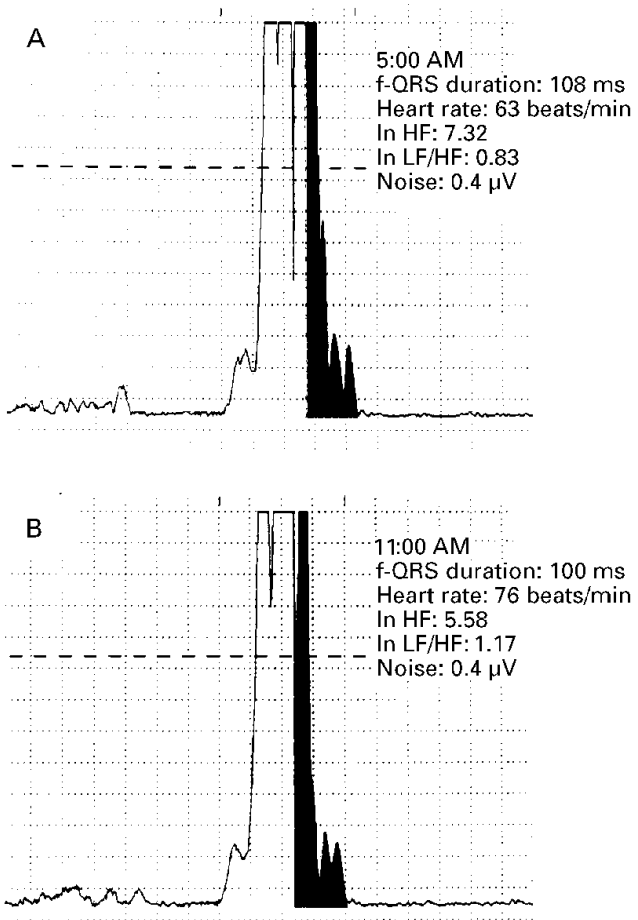

Figure 2 Signal averaged electrocardiogram recordings from a healthy 24 year old woman at 05:00 (A) and at 11:00 (B). Note that the increase of the heart rate from 63 (A) to 76 beats/min (B) was associated with an increase in ln $L F / H F$ and a decrease in $\ln H F$ and $f-Q R S$ duration, but with no change in the noise level. LF and HF, low and high frequency components, respectively, of heart rate variability; $L F / H F, L F$ to $H F$ ratio.

of heart rate variability. f-QRS duration decreased during the day and increased at night.

Spectral analysis of heart rate variability is used for quantitative assessment of autonomic activity. There is general agreement that the power of the $\mathrm{HF}$ oscillation, which is related to respiration, is a marker of efferent vagal input to the heart, and that the $\mathrm{LF} / \mathrm{HF}$ ratio is a marker of sympathetic tone. LF power is an indicator of the sympathovagal balance..$^{9-11}$ It is well established that heart rate and heart rate variability have a circadian rhythm. ${ }^{12-14}$ We evaluated the $\mathrm{f}-\mathrm{QRS}$ duration as a function of heart rate variability during routine daily activity. f-QRS duration showed a significant negative correlation with the heart rate and the $\mathrm{LF} / \mathrm{HF}$ ratio, and a significant positive correlation with $\mathrm{HF}$, suggesting that the circadian variation of the $\mathrm{f}-\mathrm{QRS}$ duration is closely related to the circadian fluctuation in heart rate or autonomic nerve activity, or both. Previous studies have shown that atrial pacing has no effect on saECG parameters in patients with coronary artery disease or a history of ventricular tachycardia or cardiac arrest. ${ }^{18-20}$ Infusion of isoprenaline ${ }^{7}$ and exercise ${ }^{6}$ or tilt $^{7}$ induced sympathetic activation shorten the f-QRS duration. Thus the shortening of $\mathrm{f}-\mathrm{QRS}$ duration during the daytime may not have been related to the increase in heart rate itself, but rather to increased sympathetic activity or decreased parasympathetic activity.

One of the most important determinants of QRS duration is ventricular conduction.
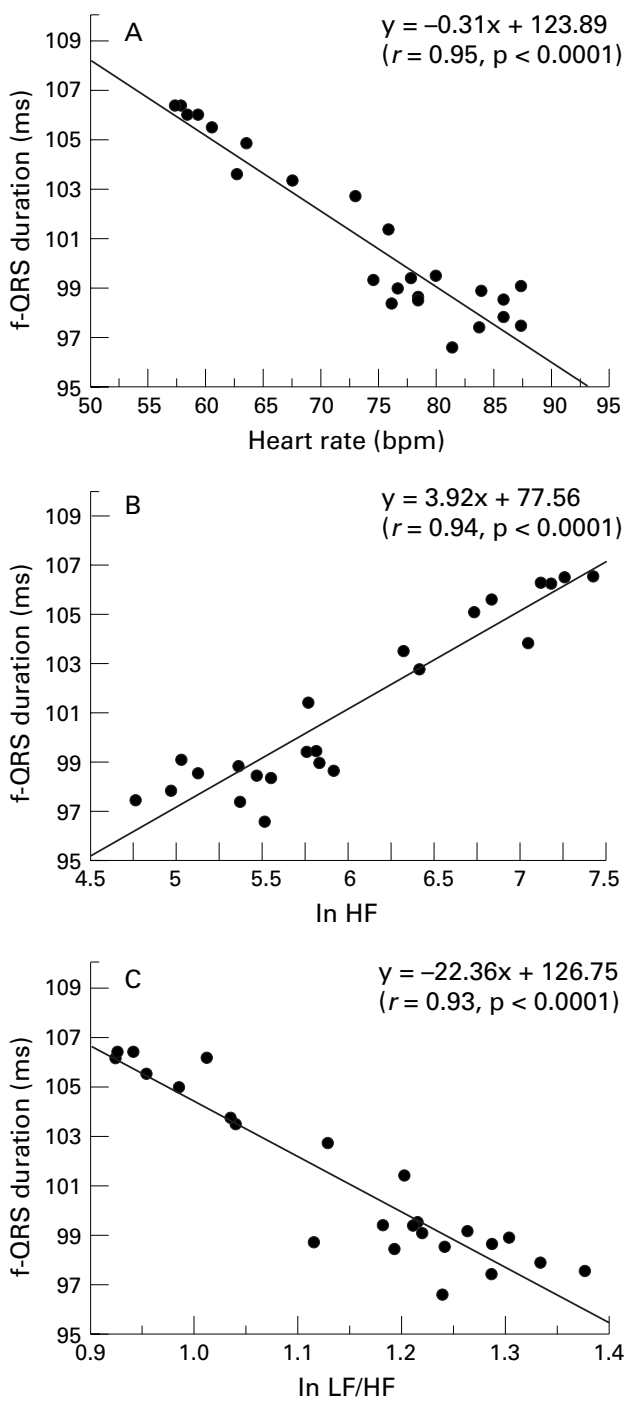

Figure 3 Correlations between the hourly means of the $f$-QRS duration and heart rate $(A), \ln H F(B)$, and $\ln$ $L F / H F(C)$ in 20 subjects. $L F$ and $H F$, low and high frequency components, respectively, of heart rate variability; $L F / H F, L F$ to $H F$ ratio.

Munger et al showed that $\beta$ adrenergic modulation of cardiac conduction was voltage dependent and that isoprenaline shortened the conduction time at the normal resting potential, but caused additional slowing of conduction in depolarised canine Purkinje fibres. ${ }^{21}$ Ono et al reported that isoprenaline increased or decreased the sodium current in canine, rabbit, and guinea pig myocytes depending on the experimental conditions of the holding and the test potential. ${ }^{22}$ The effect of $\beta$ adrenergic stimulation on ventricular conduction in vivo remains to be studied. Our data suggest that increased sympathetic tone or decreased parasympathetic tone, or both, enhances ventricular conduction during routine daily activity in healthy subjects.

An important limitation of this study is the noise level of the saECG owing to the use of Holter monitoring. The noise level may influence determinations of the f-QRS duration. ${ }^{23}$ We had to exclude 24 subjects from the analysis because of relatively high noise levels. However, the alteration in the $f-Q R S$ 
duration in response to changes in the heart rate or heart rate variability was greater than the expected change caused by differences in the noise level.

The saECG is a useful non-invasive test for identifying areas of slowed conduction that are a prerequisite for reentrant ventricular arrhythmias. ${ }^{1-5}$ Although the substrate or late potential identified by the saECG has been assumed to be fixed, our results suggest that the saECG has a circadian rhythm and may alter with changes in the autonomic tone. However, we examined only young healthy subjects. Further studies are needed to evaluate the circadian rhythm of the saECG and the effects of autonomic tone on saECG in patients with heart disease.

1 Simson MB. Use of signals in the terminal QRS complex to identify patients with ventricular tachycardia after myocardial infarction. Circulation 1981;64:235-42.

2 Kanovsky MS, Falcone RA, Dresden CA, et al. Identification of patients with ventricular tachycardia after myocardial infarction: signal-averaged electrocardiogram, Holter monitoring, and cardiac catheterization. Circulation 1984; 70:264-70

3 Gomes JA, Winters SL, Stewart D, et al. A new noninvasive index to predict sustained ventricular tachycardia and sudden death in the first year after myocardial infarction: based on signal-averaged electrocardiogram, radionuclide ejec-
tion fraction and Holter monitoring. $f \mathrm{Am}$ Coll Cardiol tion fraction and

4 Steinberg JS, Regan A, Sciacca RR, et al. Predicting arrhythmic events after acute myocardial infarction using the signal-averaged electrocardiogram. Am F Cardiol 1992; 69:13-21.

5 Mancini DM, Wong KL, Simson MB. Prognostic value of an abnormal signal-averaged electrocardiogram in patients with nonischemic congestive cardiomyopathy. Circulation 1993;87:1083-92.

6 Smith GS, Vacek JL, Wilson DB. Exercise-induced alterations of signal-averaged electrocardiograms in marathon runners. Am Heart f 1989;118:1198-202.

7 Goldberger JJ, Ahmed MW, Parker MA, et al. Assessment of effects of autonomic stimulation and blockade on the effects of autonomic stimulation and blockade on the
signal-averaged electrocardiogram. Circulation 1994;89: 1656-64.
8 Nakagawa $\mathrm{M}$, Oda $\mathrm{M}$, Iwao $\mathrm{T}$, et al. Signal-averaged electrocardiogram shows a heart rate dependent diurnal variation in healthy subjects. fpn Heart $\mathcal{f}$ 1998;39:147-52.

9 Pagani M, Lombardi F, Guzzetti S, et al. Power spectral analysis of heart rate and arterial pressure variabilities as a marker of sympatho-vagal interaction in man and conscious dog. Circ Res 1986;59:178-93.

10 Malliani A, Pagani M, Lombardi F, et al. Cardiovascular neural regulation explored in the frequency domain. Circulation 1991;84:482-92.

11 Hayano J, Sakakibara Y, Yamada M, et al. Decreased magnitude of heart rate spectral components in coronary artery disease-its relation to angiographic severity. Circulation 1990;81:1217-24

12 Furlan R, Guzzetti S, Crivellaro W, et al. Continuous 24-hour assessment of the neural regulation of systemic arterial pressure and RR variabilities in ambulant subjects. Circulation 1990;81:537-47.

13 Lombardi F, Sandrone G, Mortara A, et al. Circadian variation of spectral indices of heart rate variability after myocardial infarction. Am Heart $\mathcal{F}$ 1992;123:1521-9.

14 Huikuri HV, Niemelä MJ, Ojala S, et al. Circadian rhythms of frequency domain measures of heart rate variability in healthy subjects and patients with coronary artery disease: effects of arousal and upright posture. Circulation 1994;90: 121-6.

15 Quyyumi AA. Circadian rhythms in cardiovascular disease. Am Heart f 1990;120:726-33.

16 Wood MA, Simpson PM, London WB, et al. Circadian pattern of ventricular tachyarrhythmias in patients with implantable cardioverter-defibrillators. $f \mathrm{Am}$ Coll Cardiol 1995;25:901-7.

17 Nelson W, Tong YL, Lee JK, et al. Methods for cosinor-rhythmometry. Chronobiologia 1979;6:305-23.

8 Greenspon AJ, Volosin K. The effects of atrial pacing on the signal-averaged electrocardiogram in patients with coronary artery disease. Am Heart f 1990;119:29-34.

19 Kremers MS, Black WH, Lange R, et al. Electrocardiographic signal-averaging during atrial pacing and effect of cycle length on the terminal QRS in patients with and without inducible ventricular tachycardia. Am $f$ Cardiol 1990;66:1095-8.

20 Engel TR, Pierce DL, Murphy SP. Variation in late potentials and reproducibility of their measurement. Prog Cardiovasc Dis 1993;35:247-62.

21 Munger TM, Johnson SB, Packer DL. Voltage dependence of $\beta$-adrenergic modulation of conduction in the canine Purkinje fiber. Circ Res 1994;75:511-19.

22 Ono K, Fozzard HA, Hanck DA. Mechanism of cAMPdependent modulation of cardiac sodium channel current kinetics. Circ Res 1993;72:807-15.

23 Steinberg JS, Bigger JT. Importance of the endpoint of noise reduction in analysis of the signal-averaged electrocardiogram. Am f Cardiol 1989;63:556-60. 